\title{
The Nature of the Proteins Present in the 'Relaxed Particles' from Methionine-starved Escherichia coli A19 (Hfr rel met rns)
}

\author{
By JOHN SYKES, EMILIA METCALF AND JANET D. PICKERING* \\ Department of Biochemistry, University of Sheffield, Sheffield $S_{\mathrm{I}} \mathrm{2TN}$
}

(Received 26 March 1976)

\begin{abstract}
SUMMARY
The 'relaxed particles' formed during methionine starvation of Escherichia coli AI9 (Hfr rel met rns) have been isolated by large-scale rate-zonal density gradient ultracentrifugation. The proteins and rRNA species associated with these particles have been examined.

The rRNA species present are precursor and mature forms of $16 \mathrm{~S}$ and $23 \mathrm{~S}$ rRNA. The bulk of the rRNA which accumulates during starvation is found within the particles. The proteins prepared directly from the particles give strong multiple immunoprecipitates with antisera specific to $30 \mathrm{~S}$ and $50 \mathrm{~S}$ ribosomal proteins. The soluble proteins, prepared and examined in the same manner, do not give this immunological reaction. Two-dimensional electrophoresis patterns of the proteins from the particles show that the proteins co-migrate with proteins from $30 \mathrm{~S}$ and $50 \mathrm{~S}$ ribosomes and are entirely dissimilar to the proteins prepared by the same methods from the soluble fraction of the cells. On the basis of these and other observations, it is concluded that the 'relaxed particles' are not artefacts but are arrested ribosome precursors containing both rRNA and certain ribosomal proteins.

The free pool of ribosomal proteins is low in exponential-phase cells and is not significantly increased by a $2 \mathrm{~h}$ period of starvation for glucose.

The implications of these observations concerning the proteins associated with 'relaxed' and 'chloramphenicol particles' are discussed in relation to ribosome biogenesis and the stabilization of rRNA.
\end{abstract}

\section{INTRODUCTION}

Methionine starvation of the relaxed auxotroph Escherichia coli AI9 (Hfr rel met rns) [for abbreviations, see preceding paper (Sykes, Metcalf \& Pickering, 1977)] dissociates RNA synthesis from protein synthesis. RNA synthesis continues until the cellular RNA content has reached two to three times the pre-starvation amount whilst protein synthesis is depressed to only 5 to $10 \%$ of the normal exponential rate. Low molecular weight proteins are preferentially synthesized during starvation of these relaxed strains (Goodman, Manor \& Rombauts, 1969; Brunschede \& Bremer, I97I). Centrifugal fractionation of extracts from the cells as starvation proceeds reveals the steady accumulation of abnormal ribonucleoprotein particles, 'relaxed particles', sedimenting between 14 and $30 \mathrm{~S}$ (Dagley, Turnock \& Wild, 1963). During methionine starvation, all the normal cellular RNA species continue to be synthesized and since few new mature ribosomes are formed the primary reason for the steady increase in the cellular RNA content is the accumulation of pi $6 \mathrm{~S}$ and p23S rRNA (Adesnik \& Levinthal, 1969; Chang \& Irr, 1973; Dean \& Sykes, 1974) which may be sub-methylated (Osawa et al., 1969). These precursor RNA forms are relatively

* Present address: Department of Biochemistry, University of Leeds, Leeds 2. 
stable during the starvation period, and when the required amino acid is restored, growth resumes and the precursor rRNAs are converted to their mature forms without degradation (Chang \& Irr, 1973). The period immediately following the restoration of the required amino acid to the starved culture is notable for the temporary suppression of RNA synthesis, the preferential synthesis of certain ribosomal proteins and the loss of the 'relaxed particles' (Nakada, I965; Goodman et al., 1969). Nakada \& Unowsky (1966) have shown that the 'relaxed particles' will combine with solubilized ribosomal proteins in vitro to form functional ribosomes.

The events associated with methionine starvation and recovery of the relaxed strain closely parallel those observed during chloramphenicol inhibition. However, the possibility that the 'relaxed particles' may be arrested precursors has never been fully confirmed nor seriously questioned although by inference from the earlier observations with 'chloramphenicol particles' they may be artefacts (Schleif, I968; Yoshida \& Osawa, I968).

The properties of the rRNA species which accumulate during starvation and their behaviour on recovery are entirely consistent with their being sub-methylated but otherwise normal precursor rRNAs. These rRNAs are found within the 'relaxed particles' in association with proteins which have been reported to have similar mobilities in one-dimensional polyacrylamide gel electrophoresis to some ribosomal proteins (Nakada, 1967). There are clearly many points of similarity between the response to chloramphenicol treatment and methionine starvation in $E$. coli. With the $E$. coli AI9 strain used in previous experiments with chloramphenicol (Sykes et al., 1977), it is possible to produce 'relaxed particles' and so directly compare the nature of the proteins associated with the RNA in the particles produced by genetic and phenotypic relaxation in the same organism.

\section{METHODS}

Organism and growth conditions. The organism, materials and techniques used were as described in the preceding paper (Sykes et al., 1977) except that the period of chloramphenicol treatment was replaced by a $2 \mathrm{~h}$ period of starvation in complete medium lacking methionine. During starvation the absorbance of the culture at $540 \mathrm{~nm}$ increased by $35.3 \%$ (average of eight experiments).

All the other methods employed were as described previously, with 'relaxed particles' RI, R2 and R3 replacing references to 'chloramphenicol particles'.

\section{RESULTS}

\section{Zonal and analytical ultracentrifugation}

Figure I $(a)$ shows the analytical ultracentrifuge diagram for a crude cell-free extract from $E$. coli al9 cells starved for $2 \mathrm{~h}$ in complete medium lacking methionine. Comparison with the corresponding pattern for control, exponentially growing cells [see Fig. I $a$, preceding paper (Sykes et al., 1977)] shows that the 'relaxed particles' sediment in the region to to $30 \mathrm{~S}$ just like the 'chloramphenicol particles' (see Fig. $2 a$, preceding paper). Figure I $(b)$ shows the $E_{260}$ profile for the gradient recovered from the zonal ultracentrifuge run with the supernatant fraction from this crude extract. The samples from the gradient pooled to provide 'relaxed particle' preparations $\mathrm{R}_{1}, \mathrm{R}_{2}$ and $\mathrm{R}_{3}$ are indicated. Similarly, Fig. I (c) shows the $E_{260}$ profile for the pellet fraction and the samples pooled to provide further $\mathrm{R}_{1}, \mathrm{R}_{2}$ and $\mathrm{R}_{3}$ material and also $50 \mathrm{~S}$ ribosomes from methionine-starved cells [5oS $\left(\mathrm{MET}^{-}\right)$].

The analytical and zonal ultracentrifuge profiles for extracts from AI9 cells starved for 
(a)
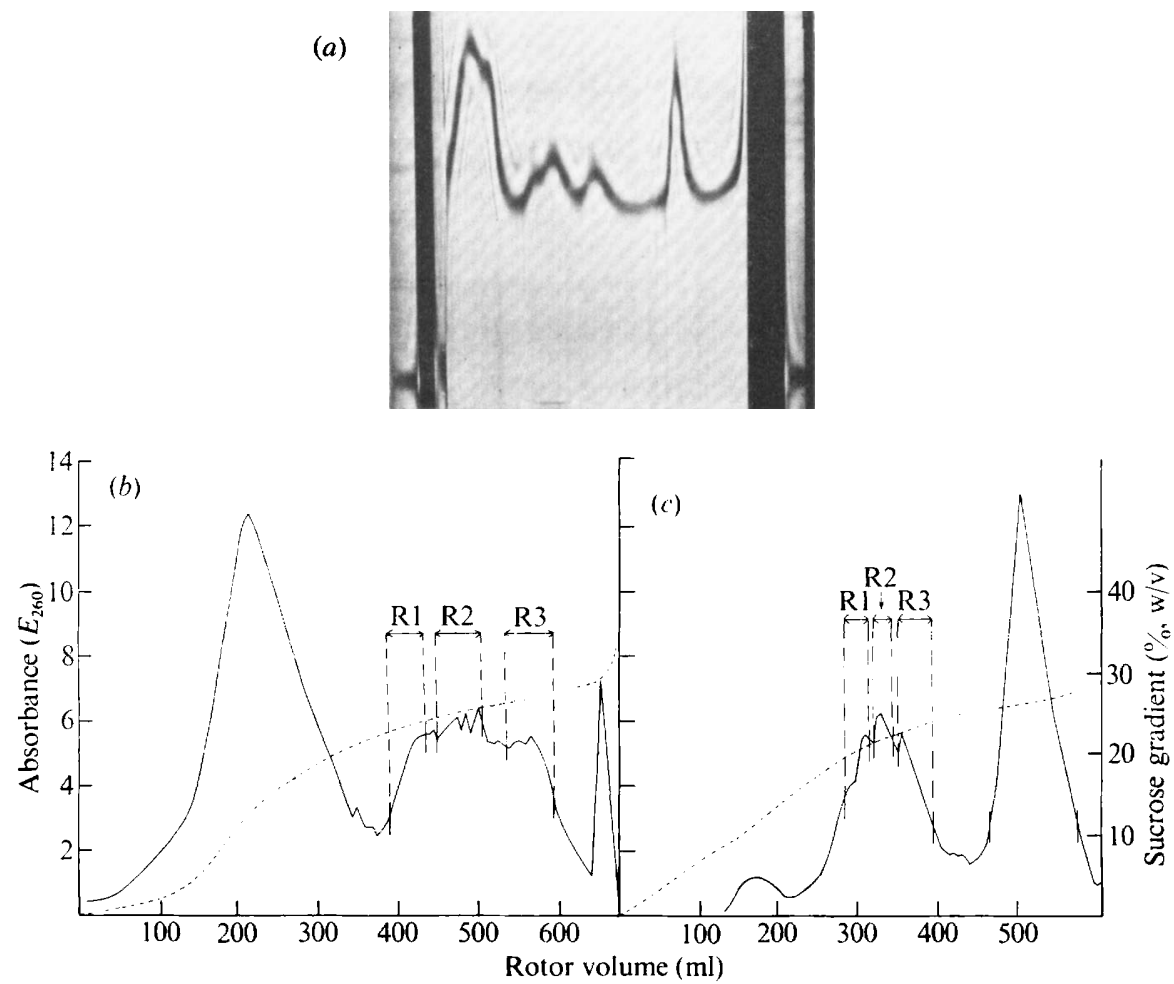

Fig. I. Analytical schlieren and zonal ultracentrifuge gradient absorbance profiles for extracts from exponential-phase cells of E. coli AI9 after $2 \mathrm{~h}$ in complete medium lacking methionine. Sedimentation is from left to right.

(a) Analytical ultracentrifuge schlieren diagram for the crude cell-free extract from methioninestarved cells. Protein concentration $10.0 \mathrm{mg} \mathrm{ml}^{-1}$; temperature $20.9{ }^{\circ} \mathrm{C}$; bar angle $30^{\circ}$; photograph taken after $20 \mathrm{~min}$ at $50740 \mathrm{rev}$. min $^{-1}$. The 'relaxed particles' are seen, by comparison with Fig. I (a) (preceding paper), to be sedimenting between the leading $50 \mathrm{~S}$ ribosome boundary and the large, slowest moving boundary.

(b) Rate-zonal ultracentrifuge density gradient absorbance profile at $260 \mathrm{~nm}$ (continuous line) for the supernatant fraction from $(a)$. The samples from the gradient pooled to provide 'relaxed particles' $\mathrm{R}_{1}, \mathrm{R}_{2}$ and $\mathrm{R}_{3}$ are indicated. Run conditions: MSE Al-r 4 rotor; load $250 \mathrm{mg}$ total protein; $24 \mathrm{~h}$ at $30000 \mathrm{rev}$. $\min ^{-1} ; 5{ }^{\circ} \mathrm{C}$; gradient to to $35 \%$ (w/v) sucrose in TMN buffer hyperbolic with radius (dashed line indicates the gradient at the end of run).

(c) Rate-zonal ultracentrifuge density gradient absorbance profile at $260 \mathrm{~nm}$ (continuous line) for the pellet fraction from $(a)$. The samples from the gradient pooled to provide additional RI, $\mathrm{R}_{2}$ and $\mathrm{R}_{3}$ material are shown together with those for the $50 \mathrm{~S}^{\left(\mathrm{MET}^{-}\right)}$ribosomes. Run conditions: MSE Al-I4 rotor; load $264 \mathrm{mg}$ ribosome equivalents; $16 \mathrm{~h}$ at 26000 rev. $\min ^{-1} ; 5{ }^{\circ} \mathrm{C}$; gradient to to $35 \%(\mathrm{w} / \mathrm{v})$ sucrose in TMN buffer hyperbolic with radius (dashed line indicates the gradient at end of run).

glucose for $2 \mathrm{~h}$ were identical to those shown for control cells (see Fig. I $a, b, c$ preceding paper). The soluble proteins used in later experiments were prepared from the pooled zonal gradient fractions containing the large, slowly sedimenting boundary material from the centrifugation of the supernatant fractions from these cells (compare Fig. I $b$, preceding paper).

$r R N A$ species present in samples from methionine-starved E. coli AI9

Comparison of the electrophoretograms for the total rRNA from fully supplemented exponential-phase cells (Fig. $3 a$, preceding paper) and from methionine-starved cells (Fig. 2a) indicates that precursor RNA, particularly pi6S rRNA which is well resolved, 


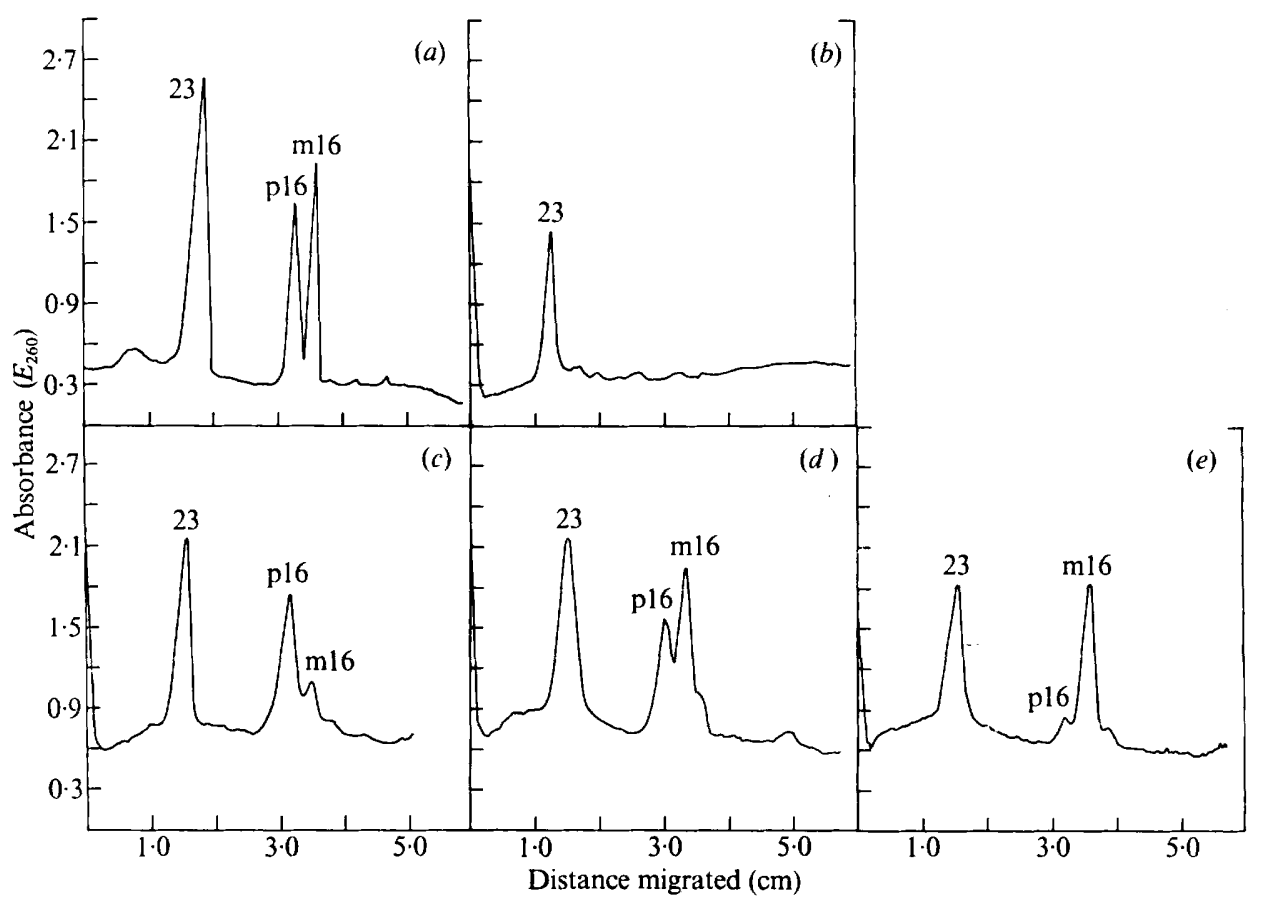

Fig. 2. Absorbance profiles at $260 \mathrm{~nm}$ for the electrophoretic separation of rRNA preparations in polyacrylamide gels. The rRNA preparations were extracted from the cell-free extracts and gradient fractions, electrophoresed and scanned as described in the preceding paper (Sykes et al., 1977). (a) Total rRNA $(50 \mu \mathrm{g})$ from crude cell-free extracts of exponential-phase cells of $E$. coli AI9 $2 \mathrm{~h}$ after transfer to fresh growth medium lacking methionine. (b) rRNA $(23.5 \mu \mathrm{g})$ from $50 \mathrm{~S}$ $\left(\mathrm{MET}^{-}\right)$ribosomes recovered from the zonal ultracentrifuge (see Fig. $\mathrm{I} c$ ). (c) rRNA (40 $\mu \mathrm{g}$ ) from 'relaxed particle' region RI (see Fig. I $b, c)$. (d) rRNA (30 $\mu \mathrm{g})$ from 'relaxed particle' region R2 (see Fig. I $b, c)$. (e) rRNA $(28 \mu \mathrm{g})$ from 'relaxed particle' region $\mathrm{R}_{3}$ (see Fig. I $b, c$ ).

accumulates within the cells as the starvation proceeds, as was found for chloramphenicol inhibition. Figure $2(b)$ shows that intact $23 \mathrm{~S}$ rRNA remains within the $50 \mathrm{~S}\left(\mathrm{MET}^{-}\right)$ ribosomes that are still intact after $2 \mathrm{~h}$ starvation. The electrophoretograms for the RNA from 'relaxed particles' $\mathrm{R}_{1}, \mathrm{R}_{2}$ and $\mathrm{R}_{3}$ (Fig. $2 c, d, e$ ) reveal that the bulk of the precursor I6S rRNA which accumulates during starvation is associated with the particles. RI (Fig. 2c) contains a high proportion of $23 \mathrm{~S}$ and pI6S rRNA indicating the presence of precursor RNA components of $50 \mathrm{~S}$ and $30 \mathrm{~S}$ ribosomes in this region. R2 (Fig. $2 d$ ) is similar although in this the proportions of pI6S and mI6S rRNA are not the same as in RI. R3 (Fig. 2e) has a predominance of mI6S rRNA and $23 \mathrm{~S}$ rRNA.

From these electrophoretograms, we conclude that precursor rRNA species accumulate in the cells during methionine starvation, and that the RNA which accumulates is associated with the 'relaxed particles'. The relaxed particle fractions taken in these experiments are clearly complex and embrace different proportions of RNA precursors of both $30 \mathrm{~S}$ and $50 \mathrm{~S}$ ribosomes. As the sedimentation coefficient increases through the particle region the proportion of precursor I6S rRNA diminishes. A further notable feature is the relative stability of the RNA from region RI of the 'relaxed particles' compared with that from the corresponding region $\mathrm{PI}$ of 'chloramphenicol particles'. 
(a) RI proteins

$50 \mathrm{~S}$ antiserum

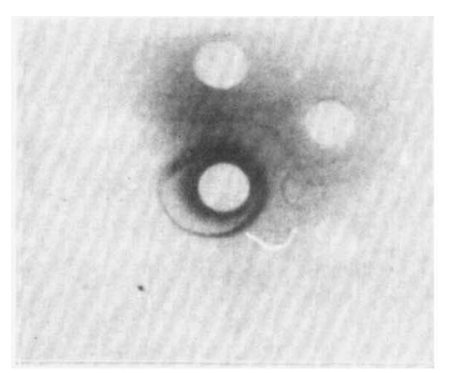

(b) $\mathrm{R} 2$ proteins

(c) $\mathrm{R}_{3}$ proteins

\section{(d) Soluble proteins}
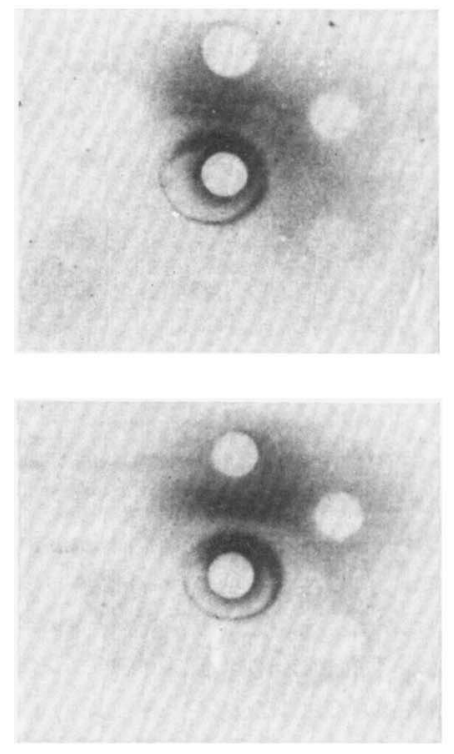

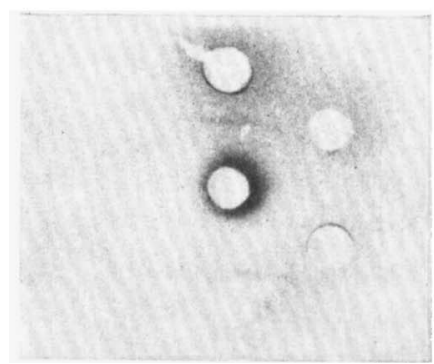

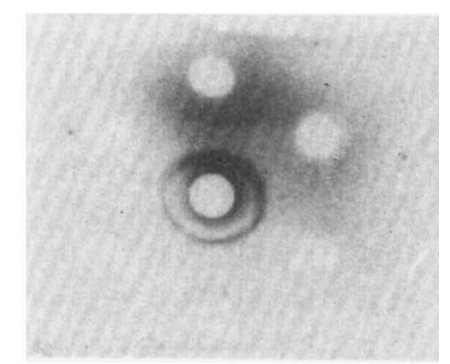

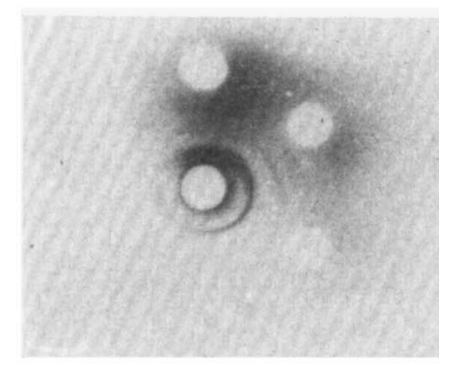

3oS antiserum
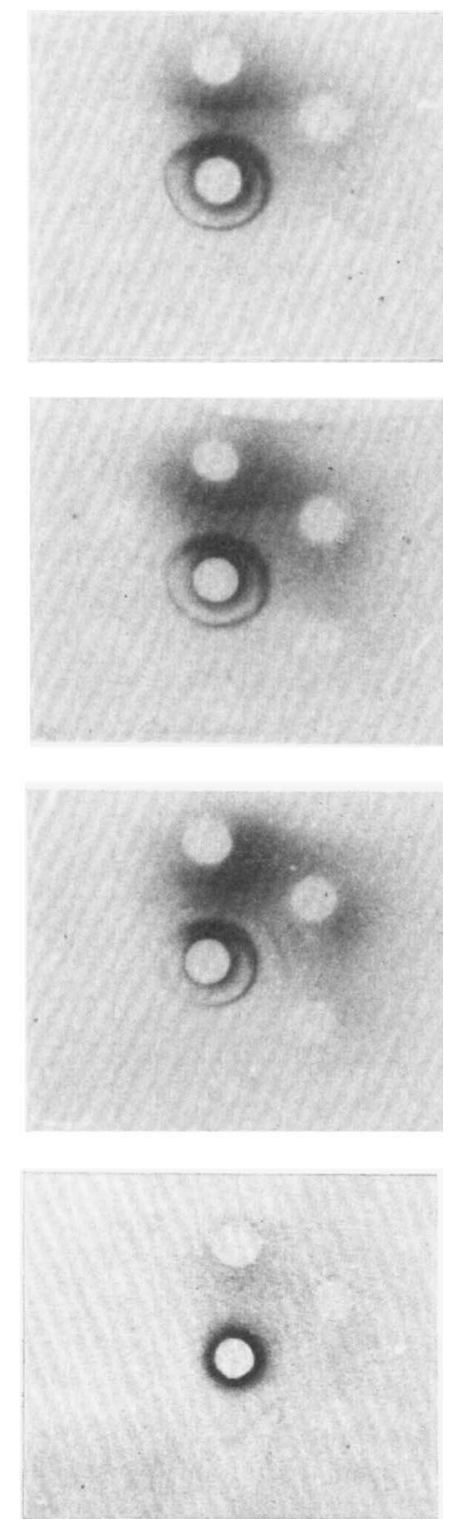

Fig. 3. Immunoprecipitates formed during double diffusion in one dimension between proteins from the soluble fraction of glucose-starved E. coli AI 9 and from the 'relaxed particles' $\mathrm{RI}_{1}, \mathrm{R}_{2}$ and $\mathrm{R}_{3}$ and antisera specific to $30 \mathrm{~S}$ or $50 \mathrm{~S}$ ribosomal proteins. Undiluted antiserum to $30 \mathrm{~S}$ (right) or $50 S$ proteins (left) was in the topmost well ( 12 o'clock) and serial dilutions $(\mathrm{I}: \mathrm{I})$ were arranged clockwise in the surrounding wells. Proteins were in the centre well: $(a)$ proteins from $\mathbf{R}_{\mathrm{I}} ;(b)$ proteins from $\mathrm{R}_{2}$; $(c)$ proteins from $\mathrm{R}_{3}$; and $(d)$ proteins prepared by ribonuclease treatment of the soluble fraction from glucose-starved AI 9. 


\section{Immunological properties of the proteins associated with the 'relaxed particles' and the soluble fraction from glucose-starved cells}

The raising of specific antisera to $50 \mathrm{~S}$ and $30 \mathrm{~S}$ ribosomal proteins of E. coli AI9 and their immunological properties are described in the preceding paper. When these antisera were tested against the proteins isolated from the 'relaxed particles' $R_{1}, R_{2}$ and $R_{3}$, they gave strong multiple immunoprecipitates with each particle at all dilutions of the respective antisera (Fig. $3 a, b, c$ ). This result unequivocally establishes the presence of both $50 \mathrm{~S}$ and $30 \mathrm{~S}$ ribosomal proteins throughout the 'relaxed particle' region. This is consistent with the finding of both rRNA precursors throughout the particle region and with the electrophoresis results (see below).

The immunological and protein electrophoresis experiments with the proteins of the soluble fraction from exponentially growing cells, described in the preceding paper, suggested a low level of free ribosomal proteins. It was therefore of interest to see if the level could be raised during a period of minimal growth such as occurs in chloramphenicol-inhibited or methionine-starved cultures. This should provide a more meaningful assessment of the free ribosomal protein pool potentially available for precursor particle formation. Exponentially growing cultures of $E$. coli AI 9 were therefore starved for $2 \mathrm{~h}$ in a complete medium lacking glucose. The soluble proteins were then prepared from the appropriate pooled samples after zonal ultracentrifugation of the supernatant fraction from extracts of these cells. Glucose starvation was chosen since it does not lead to obvious ribosome breakdown and there is no detectable growth, RNA or protein synthesis using the usual turbidimetric and colorimetric assays. In these circumstances any preferential synthesis or turnover of preexisting ribosomal proteins may be expected to swell the free pool since there is no additional rRNA to bind and no accumulation of unusual ribonucleoproteins in the cells. The immunological response to the $50 \mathrm{~S}$ and $30 \mathrm{~S}$ protein antisera of the soluble proteins prepared from these cells by the acetic-acid and ribonuclease procedures was extremely weak (Fig. $3 d$ ) and comparable with that obtained with similar preparations from exponentially growing cells. Results for the gel electrophoresis of these proteins (see below) confirm this result. The pool of free ribosomal proteins is therefore not increased significantly by a $2 \mathrm{~h}$ period of growth inhibition due to glucose starvation.

Gel electrophoresis of proteins prepared from normal $30 S$ and $50 S$ ribosomes, 'relaxed particles' $R \mathrm{I}, R_{2}$ and $R_{3}$ and the soluble cell proteins from control and glucose-starved cells

The two-dimensional gel electrophoresis patterns for normal $30 \mathrm{~S}$ and $50 \mathrm{~S}$ ribosomal proteins and the soluble proteins from exponentially growing cells are shown in Fig. 5( $a, b$, $c$ ) in the preceding paper. The corresponding patterns for the proteins isolated from 'relaxed particles' $\mathrm{R} \mathbf{I}, \mathrm{R}_{2}$ and $\mathrm{R}_{3}$ are shown in Fig. 4( $\left.a, b, c\right)$. A comparison of these patterns shows that the proteins from the 'relaxed particles' are in toto quite distinct from those in the soluble protein fraction of the cell and closely resemble the $30 \mathrm{~S}$ and $50 \mathrm{~S}$ ribosomal protein patterns. Most of the proteins in the particle regions are basic, and have relatively low molecular weights. These results, in conjunction with the immunological observations, establish that the proteins associated with the 'relaxed particles' are entirely ribosomal in nature.

The number of proteins associated with the rRNA species in the particles increases with the increasing sedimentation coefficient of the particles. Particle RI (Fig. 4a) has five clearly discernible basic proteins and one acidic one in association with the mainly pI6S 


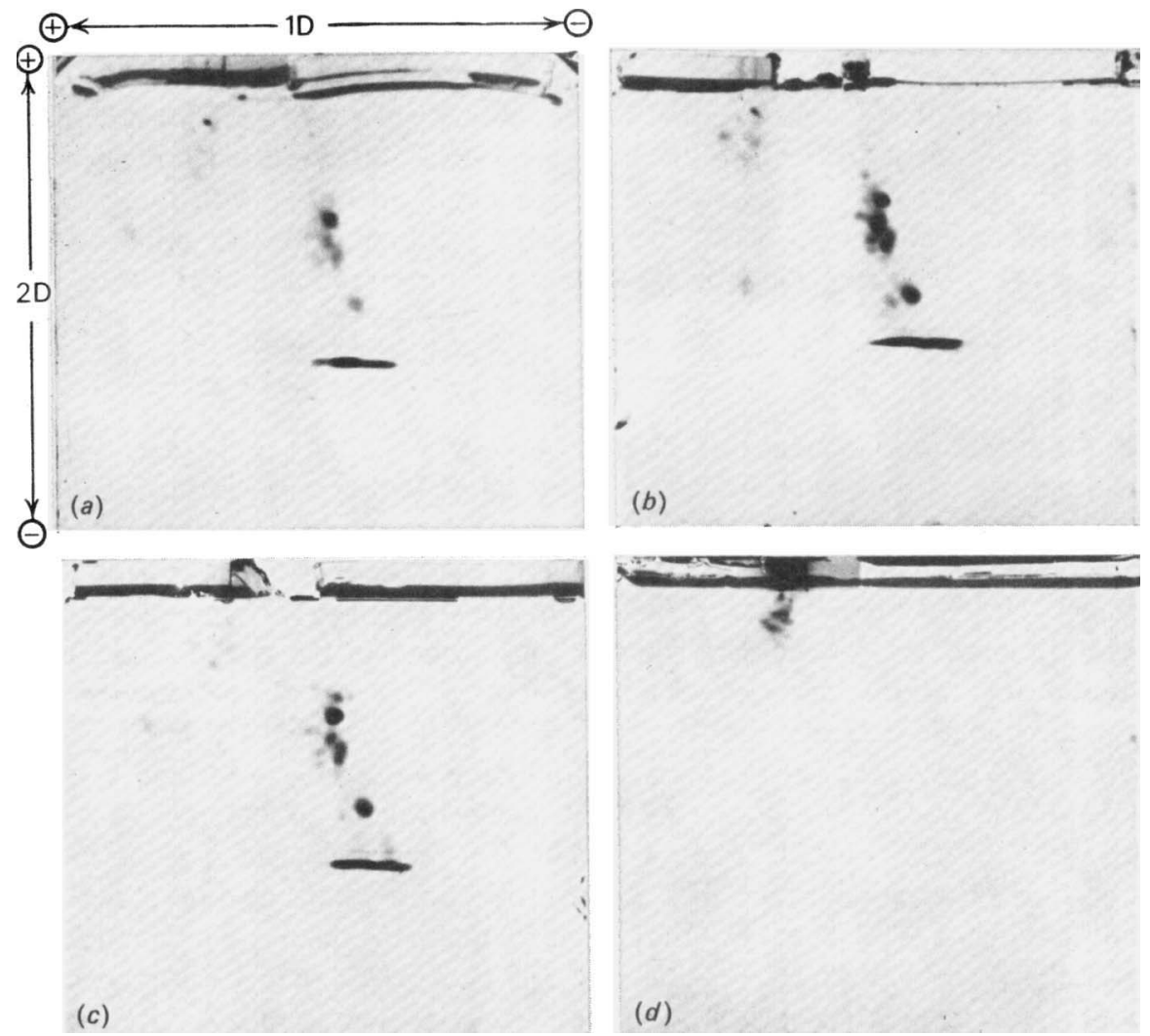

Fig. 4. Two-dimensional electrophoresis patterns for the proteins prepared from the 'relaxed particles' from methionine-starved $E$. coli AI 9 and the soluble fraction from glucose-starved cells. All the proteins were prepared as described in the preceding paper (Sykes et al., 1977) and electrophoresis followed the procedure of Kaltschmidt \& Wittmann (1970). (a) Proteins from 'relaxed particle' RI, I $80 \mu \mathrm{g}$ total protein loaded. (b) Proteins from 'relaxed particle' R2, $200 \mu \mathrm{g}$ total protein loaded. (c) Proteins from 'relaxed particle' $\mathrm{R}_{3}, 240 \mu \mathrm{g}$ total protein loaded. (d) Soluble proteins prepared via ribonuclease treatment from glucose-starved $E$. coli A19, $219 \mu \mathrm{g}$ total protein loaded.

rRNA and $23 \mathrm{~S}$ rRNA present in this region. Particle region P2 (Fig. $4 b$ ) has $\mathrm{I} 2$ basic proteins and two to three acidic ones, and $\mathrm{P}_{3}$ (Fig. $4 c$ ) has $\mathrm{I}_{4}$ basic proteins and three acidic ones clearly resolved.

The majority of the proteins in region $\mathrm{R}_{3}$ co-migrate with the $30 \mathrm{~S}$ proteins. This observation is consistent with the high proportion of mI6S rRNA in this region and probably indicates the presence of mature $30 \mathrm{~S}$ and late precursors of $30 \mathrm{~S}$ ribosomes in this fastest sedimenting 'relaxed particle' region. The proteins in region $\mathrm{R} I$ also co-migrate mainly with the $30 \mathrm{~S}$ proteins. Since pI6S rRNA predominates in this region (Fig. $2 c$ ) $\mathrm{RI}$ is biassed towards a $30 \mathrm{~S}$ ribosome precursor.

$50 \mathrm{~S}$ proteins are not as evident in the electrophoretograms of the proteins from the relaxed particles' as they are in those from the 'chloramphenicol particles'. Chloramphenicol particle region $\mathrm{P}_{3}$ embraces far more ribosomal protein species than 'relaxed particle' region $\mathrm{R}_{3}$ (compare Fig. $4 c$ with Fig. $5 f$ in the preceding paper) although $\mathrm{P}_{3}$ has relatively more pi6S rRNA and less $23 \mathrm{~S}$ rRNA than R3 (compare Fig. $2 e$ with Fig. $3 f$ in 
the preceding paper). Nevertheless $23 \mathrm{~S}$ rRNA is present throughout the 'relaxed particle' region and the immunological evidence shows the presence of $50 \mathrm{~S}$ proteins throughout the region.

Figure $4(d)$ shows the two-dimensional electrophoretic pattern of proteins obtained from the soluble fraction of $E$. coli AI9 following a period of $2 \mathrm{~h}$ starvation for glucose in an otherwise complete growth medium. A comparison of thisFigure with Fig. 5(a) in the preceding paper indicates that a period of zero growth does not raise the pool of free ribosomal proteins to a level detectable by electrophoretic or immunological analysis.

\section{DISCUSSION}

The results in this and the preceding paper show that the parallelism between phenotypic and genetic relaxation and restoration of the control of RNA synthesis in $E$. coli extends beyond the points described in the Introductions to the papers. In both types of relaxation the particles which accumulate contain ribosomal rRNA species, particularly the precursor forms, in association with ribosomal proteins. Proteins with the two-dimensional electrophoretic and immunological characteristics of those found in the soluble fraction of the cell are not found in the particles which accumulate during relaxation. The electrophoretic and immunological analyses show that all the proteins in the particles are ribosomal, either $30 \mathrm{~S}$ or $50 \mathrm{~S}$ proteins. The particles are therefore not artefacts formed between the rRNA synthesized during relaxation and the soluble proteins of the cell, as previously concluded (Schleif, I968; Yoshida \& Osawa, I968). The proteins in the unusual ribonucleoproteins produced during relaxation of RNA control by $\mathrm{Co}^{2+}$ have also been shown to be ribosomal (Blundell \& Wild, 1973). All the evidence concerning the formation and behaviour of the particles formed during the phenomena of phenotypic or genetic relaxation and restoration of control of RNA synthesis is therefore consistent with those particles being arrested ribosome precursors as suggested by Dagley et al. (1962). During relaxation, RNA synthesis continues unabated and protein synthesis drops to 5 to $10 \%$ of the exponential rate. The proportion of this synthesis diverted to ribosomal proteins is twice as great during methionine starvation as the corresponding proportion during exponential growth. The proportions of the ribosomal proteins produced are also distorted compared with the co-ordinated synthesis of exponential growth since a few proteins are produced at very high relative rates (Goodman et al., 1969; Goodman, 1970). The rRNA accumulating during relaxation is formed in the usual precursor forms within the particles although it may be sub-methylated in methionine-starved cultures (Adesnik \& Levinthal, 1969; Lowry \& Dahlberg, I97I; this paper). Recent studies on the specificity of interaction and the chronology of association of ribosomal proteins with mature and nascent rRNA in vitro (see Zimmermann, 1974, and Nomura \& Held, 1974, for reviews; Nikolaev \& Schlessinger, 1974) and in vivo (Nierhaus, Bordasch \& Homann, 1973) show that an association between the nascent precursor rRNA and ribosmal proteins would be more likely than a non-specific association between the rRNA and the soluble proteins of the cell. In this case the particles steadily accumulating during relaxation would have all the characteristics of ribosome precursors, i.e. precursor rRNA in association with an increasing but selected number of ribosomal proteins. The usual orderly ribosome biogenesis sequence would, therefore, be arrested at a series of different points during relaxation depending on the availability of certain ribosomal proteins (Sykes, 1966; Chang \& Irr, I973; Marvaldi et al., 1974). The points of arrest would not necessarily be the same in all relaxed states since they would depend on the size and composition of the free ribosomal protein pool (see below), the 
pattern and extent of residual protein synthesis and turnover. The RNA:protein ratios of the components of the particle region would therefore vary. The evidence in these experiments shows that the pattern of both rRNA and protein distribution differs across the particle region for methionine-starved and chloramphenicol-induced relaxation. This is also consistent with earlier observations concerning the different stabilities of these particles (Dagley et al., I963). The stabilization of the nascent $r$ RNA synthesized during relaxation may depend on its association with a critical number of specific ribosomal proteins as suggested by Chang \& Irr (1973). This, coupled with a limited supply of ribosomal proteins, would account for the abrupt halt in RNA accumulation in relaxed states. This usually occurs when the RNA content of the cell has reached two to three times the pre-relaxation level (Dalgarno \& Gros, I968). It is therefore likely that these arrested states do not correspond to the kinetic 'hold-up' points detected for normal ribosome biogenesis since the latter are not primarily determined by a limited availability of certain ribosomal proteins. Ribosomal protein synthesis is fully co-ordinated during normal growth. The particles formed during relaxed states are therefore a heterogeneous collection of nascent $50 \mathrm{~S}$ and $30 \mathrm{~S}$ ribosome intermediates. They may be titrated with ribosomal proteins in vitro to produce functional ribosomes (Nakada \& Unowsky, 1966) or in vivo converted to mature ribosomes by a preferential, skewed and complementary pattern of ribosomal protein synthesis (Nakada, 1965; Davis \& Sells, 1969).

A final point in connection with the formation of these unusual ribonucleoproteins during the relaxed control condition concerns the origin of the ribosomal proteins which are associated with the rRNA. There is very little information available on the composition of the particles and on the basis of early estimates for 'chloramphenicol particles' (Dagley \& Sykes, 1960; Nomura \& Watson, 1959) it is frequently assumed that their composition is approximately $75 \%$ RNA and $25 \%$ protein (e.g. Schleif, 1968) although lower protein values of 15 to $18 \%$ have been recorded (Yoshida \& Osawa, I968). Furthermore, since the particles material is equal to at least half the mass of ribosomes in the cell extract (see, for example, Fig. I $a$ ), by making two further assumptions i.e. that all the protein in the particles is present in the cell before relaxation commences and that it is in the form of a free pool of ribosomal protein, one can conclude that the size of this pool must be equivalent to $25 \%$ of the total ribosomal protein in the cell. This reasoning has led to an examination of the size of the free ribosomal protein pool in growing cells by two main approaches: direct measurement in particle-free supernatant fractions by immunological or electrophoretic analysis and by the kinetics of appearance of radioactive amino acids in ribosomes in pulse-chase experiments. The results have varied widely. The former methods tend to give higher estimates of the pool size as a percentage of the total ribosomal protein than the latter. Thus immunological analysis has given values of between I and $20 \%$ (Santer et al., 1968; Gupta \& Singh, 1972; Stöffler, cited by Voynow \& Kurland, 197I) and direct eletrophoretic analysis has given values of between 3 and 10\% (Voynow \& Kurland, I97I ; Subramanian, 1974). The observations in this paper support the lower estimates obtained by direct examination of the particle-free supernatants from exponentially growing cells. This is also in agreement with most estimates of the pool size made by measuring the kinetics of radioactive labelling; these fall in the range 2 to $4 \%$ (Schleif, I968; Gierer \& Gierer, I968; Gupta \& Singh, I972, Marvaldi et al., 1974; Gausing, 1974). The pool of free ribosomal proteins in exponentially growing cells therefore appears unlikely to be sufficient to satisfy the apparent protein requirement for producing the particles even though the fraction in the pool increases linearly with growth rate and its absolute concentration is proportional to the square of the growth rate (Gausing, 1974). The pool size does not appear to be significantly enlarged in 
the non-growing state of glucose starvation (this paper) and the pool size is not the same for all ribosomal proteins (Marvaldi et al., I974).

Since all the proteins associated with the particles are ribosomal (this paper), the total protein complement of the particles must arise from a combination of three potential sources. (i) The free ribosomal protein pool. From the estimates of its size in both growing and non-growing cells it seems unlikely that this could account for more than $50 \%$ of the total protein found in the particles. (ii) Breakdown of pre-existing ribosomes or selective protein detachment. No firm evidence has been found in these experiments for selective protein detachment from intact $50 \mathrm{~S}$ ribosomes. However, during chloramphenicol inhibition extensive breakdown of pre-existing ribosomes has been reported (Lef kovits \& di Girolamo, 1969; Young \& Nakada, 197I). (iii) Residual preferential synthesis of ribosomal proteins in the relaxed states coupled with an increased rate of protein turnover known to take place in low-growth conditions. The residual protein synthesis in the methionine-starved relaxed state is 5 to $10 \%$ of the full exponential rate and is skewed towards the production of a limited number of the ribosomal proteins (Goodman, 1970). Added to this, in methionine starvation the rate of protein turnover is increased to $3.6 \% \mathrm{~h}^{-1}$ (Borek, Pontecorvo \& Rittenberg, 1958), and in chloramphenicol inhibition it is known thatjprotein synthesis is not totally abolished unless exceptionally high levels (in excess of $400 \mu \mathrm{g} \mathrm{ml}^{-1}$ ) of the drug are used (Aronson \& Spielgelman, 196I). A combination of these three potential sources could therefore give rise to the limited supply of selected ribosomal proteins essential for stabilization of the precursor rRNAs in the variety of arrested precursors seen in these relaxed states. The halt in net rRNA accumulation after a period of relaxation would then be attributed to an exhaustion of these supplies of ribosomal proteins, particularly the early-binding proteins.

We are indebted to the Science Research Council for providing a studentship for J.D.P. Mr L. Milnes of this Department constructed the two-dimensional electrophoresis unit used in these experiments.

\section{REFERENCES}

Adesnik, M. \& Levinthal, C. (1969). Synthesis and maturation of ribosomal RNA in Escherichia coli. Journal of Molecular Biology 46, 28I-303.

Aronson, A. \& Spielgelman, S. (I96I). Protein and RNA synthesis in chloramphenicol inhibited Escherichia coli. Biochimica et biophysica acta $\mathbf{5 3}, 70-84$.

BLUNDEll, M. R. \& WILD, D. G. (1973). Ribosome precursors accumulated by Escherichia coli during incubation with cobalt chloride. Biochemical Journal $136,565-570$.

Borek, E., Pontecorvo, L. \& Rittenberg, D. (1958). Protein turnover in micro-organisms. Proceedings of the National Academy of Sciences of the United States of America 44, 369-374.

Brunschede, H. \& Bremer, H. (I97I). Synthesis and breakdown of proteins in Escherichia coli during amino acid starvation. Journal of Molecular Biology 57, 35-57.

ChANG, B. \& IRR, J. (I973). Maturation of ribosomal RNA in stringent and relaxed bacteria. Nature New Biology 243, 35-37.

DAGLEY, S. \& SYKES, J. (1960). Bacterial ribonucleoprotein synthesised in the presence of chloramphenicol. Biochemical Journal 74, IIP.

Dagley, S., White, A. E., Wild, D. G. \& SyKes, J. (I962). Synthesis of protein and ribosomes by bacteria. Nature, London I94, 25-27.

Dagley, S., Turnock, G. \& WiLd, D. G. (I963). The accumulation of ribonucleic acid by a mutant of Escherichia coli. Biochemical Journal 88, 555-566.

Dalgarno, L. \& Gros, F. (I968). Completion of ribosomal particles in Escherichia coli during inhibition of protein synthesis. Biochimica et biophysica acta $\mathbf{1 5 7}, 52-63$.

Davis, F. C. \& Sells, B. H. (1969). Synthesis and assembly of ribosomal protein into $50 \mathrm{~S}$ subunits during recovery from chloramphenicol treatment. Journal of Molecular Biology 39, 503-521.

DEAN, J. R. \& SYKES, J. (1974). The role of ribonuclease II in the maturation of precursor I6S ribosomal ribonucleic acid in Escherichia coli. Biochemical Journal I40, 443-450. 
GAUSING, K. (1974). Ribosomal protein in Escherichia coli: rate of synthesis and pool size at different growth rates. Molecular and General Genetics 129, 6I-75.

Gierer, L. \& Gierer, A. (1968). Synthesis of ribosomal proteins and formation of ribosomes in Escherichia coli. Journal of Molecular Biology 34, 293-303.

Goodman, D. (1970). Ribosomal protein synthesis during amino acid starvation and chloramphenicol treatment. Journal of Molecular Biology 5I, 491-499.

Goodman, D., Manor, H. \& Rombauts, W. (1969). Ribosomal protein synthesis during and after amino acid starvation in relaxed and stringent bacteria. Journal of Molecular Biology 40, 247-260.

Gupta, R. S. \& Singh, U. N. (1972). Biogenesis of ribosomes: free ribosomal protein pools in Escherichia coli. Journal of Molecular Biology 69, 279-301.

Kaltschmidt, E. \& Wittmann, H.G. (1970). Two-dimensional polyacrylamide gel electrophoresis for fingerprinting ribosomal proteins. Analytical Biochemistry 36, 40 I-4I 2.

Lefrovits, I. \& DI Girolamo, M. (1969). Properties of ribonucleoprotein particles in chloramphenicoltreated cells of Escherichia coli в. Biochimica et biophysica acta 174, 56I-565.

Lowry, C. V. \& DAhlberg, J. (197I). Structural differences between I6S ribosomal RNA in Escherichia coli and its precursor. Nature New Biology 232, 52-54.

Marvaldi, J., Pichon, J., Delaage, M. \& Marchis-Mouren, G. (1974). Individual ribosomal protein pool size and turnover rate in Escherichia coli. Journal of Molecular Biology 84, 83-96.

NAKADA, D. (I965). Formation of ribosomes by a 'relaxed' mutant of Escherichia coli. Journal of Molecular Biology 12, 695-725.

NaKaDA, D. (1967). Proteins of ribosomes formed from 'relaxed' particles. Journal of Molecular Biology 29, 473-485.

NAKADA, D. \& UNOWSKY, J. (1966). In vitro formation of functional ribosomes from the 'relaxed particles'. Proceedings of the National Academy of Sciences of the United States of America 56, 659-663.

Nierhaus, K. H., Bordasch, K. \& HomanN, H. E. (I973). In vivo assembly of Escherichia coli ribosomal proteins. Journal of Molecular Biology 74, 587-597.

Nikolaev, N. \& Schlessinger, D. (1974). Binding of ribosomal proteins to $30 \mathrm{~S}$ pre-ribosomal ribonucleic acid of Escherichia coli. Biochemistry, New York 13, 4272-4278.

Nomura, M, \& Held, W. (1974). Reconstitution of ribosomes: studies of ribosome structure, function and assembly. In Ribosomes, pp. 193-223. Edited by M. Nomura, A. Tissieres and P. Lengyel. Cold Spring Harbor, U.S.A.: Cold Spring Harbor Laboratory.

Nomura, M. \&WATson,J.D. (1959). Ribonucleoprotein particles within chloromycetin-inhibited Escherichia coli. Journal of Molecular Biology 1, 204-21 7.

Osawa, S., OTAKa, E., IтоH, H. \& FukuI, T. (1969). Biosynthesis of the 50 S ribosomal sub-unit in Escherichia coli. Journal of Molecular Biology 40, 32I-35I.

Santer, M., Ruebush, T. K., Brunt, J. V., Oldmixon, E., Hess, R., Primakof, P. \& Palade, P. (1968). Identification of a precursor pool of ribosomal protein in Escherichia coli. Journal of Bacteriology $\mathbf{9 5}$, $1355-1367$.

SCHLEIF, R. (I968). Origin of chloramphenicol particle protein. Journal of Molecular Biology 37, I I9-I 29.

Subramanian, A. (1974). Sensitive separation procedure for Escherichia coli ribosomal proteins and the resolution of high molecular weight components. European Journal of Biochemistry 45, 54I-546.

SYkeS, J. (1966). A mechanism for the regulation of ribosomal ribonucleic acid synthesis in bacteria. Journal of Theoretical Biology 12, 373-384.

Sykes, J., Metcalf, E. \& Pickering, J. D. (I977). The nature of the proteins in 'chloramphenicol particles' from Escherichia coli AI9 (Hfr rel met rns). Journal of General Microbiology 98, I-I6.

Voynow, P. \& Kurland, C. G. (I97I). Stoichiometry of the 30 S ribosomal proteins of Escherichia coli. Biochemistry, New York ro, 517-524.

YoshIDA, K.\& OSAWA, S. (1968). Origin of the protein component of chloramphenicol particles in Escherichia coli. Journal of Molecular Biology 33, 559-569.

Young, R. M. \& Nakada, D. (I97I). Defective ribosomes in chloramphenicol-treated Escherichia coli. Journal of Molecular Biology 57, 457-473.

ZimmermanN, R. (1974). RNA-protein interactions in the ribosome. In Ribosomes, pp. 225-269. Edited by M. Nomura, A. Tissieres \& P. Lengyel. Cold Spring Harbor, U.S.A.: Cold Spring Harbor Laboratory. 